\title{
Hemispheric differences in recognition memory for letters
}

\author{
KIM KIRSNER \\ University of Western Australia, Nedlands, Perth 6009, Australia
}

\begin{abstract}
An experiment was conducted to examine the relationship between hemisphere specialization and temporal changes in the status of visual and verbal codes in short-term memory. The procedure, which involved presentation of a single target letter in central vision followed by a unilateral probe, yielded a general right visual field left-hemisphere advantage for physical and name matches at stimulus onset asynchronies greater than $.05 \mathrm{sec}$. The results support the hemisphere-priming view advanced by Kinsbourne (1973) and are inconsistent with alternative accounts involving temporal changes in representations in the cerebral hemispheres.
\end{abstract}

Research into the processes involved in letter recognition has led to what might be termed "modal" models (Murdock, 1972) describing the temporal and hemispheric organization of visual and verbal codes in human information processing. With regard to temporal organization, it is now generally accepted that, following visual character presentation, a temporary visual code is rapidly superseded by a relatively durable verbal code. Support for this view comes from a variety of experimental techniques, including brief displays of letter matrices (Sperling, 1967), error analyses of serial recall data (Conrad, 1964), and letter-matching tasks involving comparisons between physical- and namematch conditions (Posner, Boies, Eichelman, \& Taylor, 1969). Similarly, with hemisphere specialization, extensive support exists for a common view. In this case, it is generally accepted that the right and left hemispheres are relatively if not absolutely specialized for visuospatial and verbal information processing, respectively. Evidence for this view also comes from experiments using letter-recognition (White, 1969) and letter-matching (Geffren, Bradshaw, \& Nettleton, 1972) tasks. An important question, therefore, and one with which this paper is concerned, involves the relationship between these models.

In an initial attempt to integrate research into hemisphere specialization and temporal changes in representation, Wilkins and Stewart (1974) found empirical support for an intuitively appealing synthesis of the models outlined above. Using a name-match task (Posner \& Keele, 1967) and central presentation of target letters, they found that at a stimulus onset asynchrony (SOA) of .10 sec, accuracy approached $100 \%$ correct, provided that the target and probe stimuli were physically identical and the probe stimulus was presented in the left visual field (LVF). At a SOA of $1.04 \mathrm{sec}$, however, while accuracy was higher in the right visual field (RVF) than in the LVF, it was insensitive to identity. Assuming, then, that subjects can use either a visual code or a name code at short SOAs, Wilkins and
Stewart concluded that, following visual character presentation, a preliminary nonverbal code is available in the right cerebral hemisphere, but that this is rapidly superseded by a verbal code in the left hemisphere.

In view of the importance of Wilkins and Stewart's (1974) tentative integration of research into coding processes and hemisphere specialization, the experiment to be reported here was designed as a replication of their study. An additional reason for replication is that in their study, Wilkins and Stewart report a unique relationship between match type (same case vs. different case) and SOA. When their data are averaged across hemifield and response hand, reaction time (RT) in their physical-match condition (740 msec) is longer than RT in their name-match condition $(724 \mathrm{msec})$ at a SOA of $.10 \mathrm{sec}$. This relationship was reversed at a SOA of $1.04 \mathrm{sec}$. In previous research, where simultaneous presentation or short SOAs have been used, physicalmatch conditions invariably enjoy a RT advantage under both central and lateralized viewing conditions (Cohen, 1972; Davis \& Schmit, 1973; Geffen et al., 1972; Posner et al., 1969).

\section{METHOD}

\section{Subjects}

Ten undergraduate females between 18 and 30 years of age completed four experimental sessions in partial fulfillment of a course requirement. The subjects included all reported themselves to be strongly right-handed on those questions in the Edinburgh Handedness Inventory (Oldfield, 1971) that have been shown to be loaded on handedness for Australian students (White \& Ashton, 1976).

\section{Design}

Five factors were included in the design. These were: (1) response hand, a between-subjects factor with five subjects per group; (2) response valence, where $\mathrm{p}(+)=.66$ and $\mathrm{p}(-)=.33$; (3) SOA, with four levels at .05, .2, .4, and .8 sec; (4) match type, with same- and different-case conditions, and (5) visual field.

\section{Procedure}

Each session comprised 480 trials with 20 trials in each 
positive or "same-name" trial and 160 negative or "differentname" trials. The sessions were divided into 10 blocks of 48 trials each, where the relevant (positive) conditions were sampled equally often in each block. Equal emphasis was placed on accuracy and speed in the instructions, and subjects responded by pressing a button with the index finger of the designated hand for same-name stimuli.

The stimulus sequence on each trial comprised: (1) a fixation cross displayed for $.60 \mathrm{sec}$, (2) a blank interval for $.10 \mathrm{sec}$, (3) a target letter displayed in central vision for $.05 \mathrm{sec}$, (4) a SOA, and (5) a single probe letter displayed in the LVF or RVF for .20 sec. A PDP-11 computer was used to control trial and stimulus randomization, stimulus display, and data acquisition.

The stimuli chosen for the experiment consisted of the letters A, B, D, F, G, and R. These were derived from the Letraset Horatio Light set for upper- and lowercase and plotted, under program control, on individual oscilloscopes with an effective screen area of $10^{2} \mathrm{~cm}$ and a resolution of $1,000^{2}$ points. The stimuli subtended approximately .8 and $1.0 \mathrm{deg}$ on the horizontal and vertical axes, respectively, and, when displayed as probes, the midpoint of each letter was presented at a visual angle of $3.0 \mathrm{deg}$ to either side of the center of the screen. The stimuli were plotted on BWD 594 oscilloscopes with P1 phosphor decaying to $10 \%$ in approximately $1 \mathrm{msec}$. Chin rests were used to insure that the subjects' eyes were correctly positioned $45 \mathrm{~cm}$ from the display and directly in line with the center of the screen.

\section{RESULTS}

The results showing mean $\mathrm{RT}$ for correct responses and percent error are summarized in Figure 1. The data shown here represent the average results for four sessions following an analysis of variance that showed that this factor produced no interactions of interest with the within-sessions variables. Each point in Figure 1 is based on approximately 800 observations.

As shown in Figure 1, the RT and accuracy data support a general RVF/left-hemisphere advantage. Apart from the $.05-\mathrm{sec}$ SOA condition, where the relative improvement in mean RT for the LVF/right-hemisphere conditions probably reflects changes in speed-accuracy

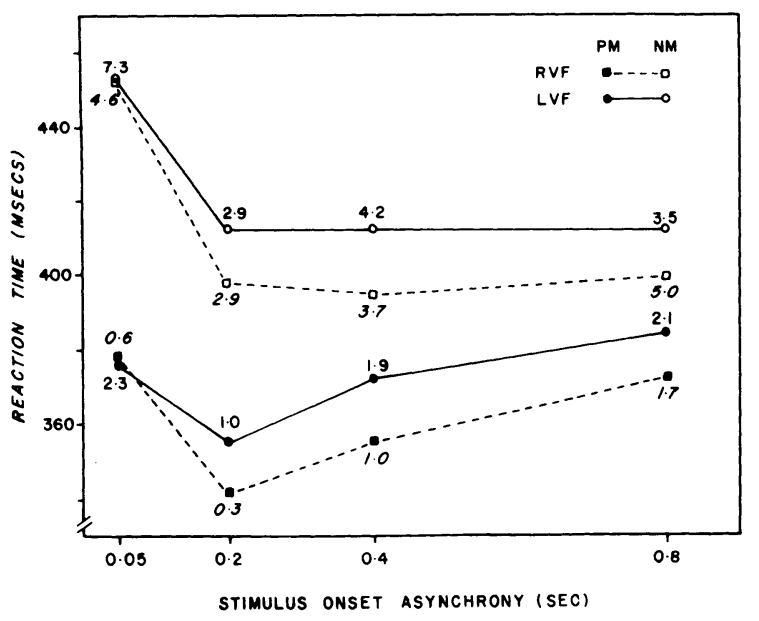

Figure 1. Speed (mean RT) and accuracy (percent error) for physical-match (PM) and name-match (NM) conditions as a function of visual field and stimulus onset asynchrony. The error data for the RVF are shown in italics. criteria, performance was generally more rapid and more accurate for RVF/left-hemisphere conditions irrespective of match type or SOA. A four-factor analysis of variance (response hand by SOA by match type by visual field) conducted on the positive data supported this summary and showed that the critical within-subjects interactions involving visual field were not significant at $\alpha=.05$. Specifically, while the main effects of SOA, match type, and visual field were all significant, the interactions between match type and visual field $[F(1,8)=.04$, $\mathrm{MSe}=139]$ and between SOA, match type, and visual field $[F(3,24)=.29, \mathrm{MSe}=204]$ were not. Two other significant interactions between response hand and visual field $[F(1,8)=25.97, \mathrm{MSe}=1,120]$ and between SOA and match type $[F(3,24)=16.11, \mathrm{MSe}=226]$ are consistent with previous research. The first of these two interactions involved a RT advantage when visual field and response hand corresponded, while the second reflected convergence between the physical- and namematch conditions as a function of increasing SOA.

As can be seen from the error data inset in Figure 1, speed and accuracy were positively correlated and, with one exception, accuracy was greater under RVF/lefthemisphere conditions for all combinations of the positive conditions. Apart from the main effects of visual field $[\mathrm{F}(1,8)=8.80, \mathrm{MSe}=2.44]$ and match type $[F(1,8)=14.69, \mathrm{MSe}=24.00]$, there were no significant main effects of interactions in the accuracy data. In the one SOA condition where mean RT for the LVF was not at a disadvantage $(.05 \mathrm{sec})$, the error rates increased by $1 \%-3 \%$, thus negating the argument that the RT result in question reflects improved accessibility for righthemisphere probes in this condition. In any case, the results are qualitatively identical for the physical- and name-match conditions.

In summary, then, although there was an overall RVF/left-hemisphere advantage in speed and accuracy, the results lend no support to the more specific temporal hypothesis that this will be preceded by a LVF/righthemisphere advantage for physical matches.

Detailed consideration of the overall error data revealed that they are consistent with the view that there may be criterion differences between the hemispheres. For the LVF/right-hemisphere data, the error rates were $3.2 \%$ and $5.8 \%$ for the positive and negative conditions, whereas the comparable rates for the RVF/ left-hemisphere errors were $2.5 \%$ and $8.7 \%$, respectively. The results support Cohen's (1973) view that the left hemisphere may be biased toward positive judgments. However, as in Cohen's study, they also suggest an interpretation of the observed visual field differences that does not involve efficiency differences between the hemispheres.

\section{DISCUSSION}

The results are in conflict with those reported by Wilkins and Stewart (1974) and lend no support to their account of temporal changes in representation in the cerebral hemispheres. 
They suggest, on the contrary, that the experimental procedure used by Wilkins and Stewart is associated with a general RVF/left-hemisphere advantage at SOAs greater than $.05 \mathrm{sec}$. Furthermore, and this finding is inconsistent with the results of studies using simultaneous presentation (Cohen, 1972; Davis \& Schmit, 1973; Geffen et al., 1972), the RVF/left-hemisphere advantage applies to physical as well as nominal identity conditions.

The presence of a general RVF/left-hemisphere advantage is consistent with the position advanced by Kinsbourne (1970, 1973) that cognitive activity lateralized to one hemisphere overflows so as to produce an advantage for the contralateral hemifield. In the present study, as naming is demanded by the nature of the task, it may be assumed that the left hemisphere is selectively activated during and after presentation of the target letter in central vision.

\section{REFERENCES}

CoHen, G. Hemisphere differences in a letter classification task. Perception \& Psychophysics, 1972, 11, 139-142.

CoHen, G. Hemisphere differences in serial versus parallel processing. Journal of Experimental Psychology, 1973, 97, 349-356.

Conrad, R. Acoustic confusions in immediate memory. British Journal of Psychology, 1964, 55, 75-84.

DAvis, R., \& Schmit, V. Visual and verbal coding in the interhemispheric transfer of information. Acta Psychologica, $1973,37,229-240$.
Geffen, G., Bradshaw, J. L., \& Nettleton, N. C. Hemispheric asymmetry: Verbal and spatial encoding of visual stimuli. Journal of Experimental Psychology, 1972, 95, 25-31.

Kinsbourne, M. The cerebral basis of lateral asymmetries in attention. Acta Psychologica, 1970, 33, 193-201.

KinsBouRne, M. The control of attention by interaction between the hemispheres. In S. Kornblum (Ed.), Attention and performance IV. New York: Academic Press, 1973.

MURDock, B. B., JR. Short-term memory. In G. H. Bower (Ed.), The psychology of learning and motivation: Advances in research and theory (Vol. 5). New York: Academic Press, 1972.

Oldfield, R. C. The assessment and analysis of handedness: The Edinburgh inventory. Neuropsychologia, 1971, 9, 97-113.

Posner, M. I., Boies, S. J., Eichelman, W. H., \& Taylor, R. L. Retention of visual and name codes of single letters. Journal of Experimental Psychology, 1969, 79, 1-16.

Posner, M. I., \& Keele, S. W. Decay of visual information from a single letter. Science, 1967, 158, 137-139.

SPERLING, G. Successive approximations to a model for shortterm memory. Acta Psychologica, 1967, 27, 285-292.

White, K., \& Ashton, R. Handedness assessment inventory. Neuropsychologia, 1976, 14, 261-264.

WhITE, M. I. Laterality differences in perception: A review. Psychological Bulletin, 1969, 72, 387-405.

Wilkins, A., \& Stewart, A. The time course of lateral asymmetries in visual perception of letters. Journal of Experimental Psychology, 1974, 102, 905-908.

(Received for publication September 6, 1978.) 